\title{
DODECAFONISMO E LINGUAGEM MUSICAL EM ADORNO
}

\author{
Luiz Antonio Serrano Junior \\ Universidade Federal de São Paulo
}

\begin{abstract}
Resumo: A semelhança entre a linguagem abstrata da música e a linguagem conceitual e significante do discurso é um dos muitos problemas estéticos e filosóficos apontados por Adorno ao longo de sua obra, e será o principal objeto desse breve artigo, que pretende discutir alguns dos pensamentos de Adorno sobre a música, em sua intrínseca e quase indistinguível relação com a linguagem. Um pouco da história da música será apresentada como introdução, assim como alguns exemplos musicais, com os quais nós tentaremos mostrar como os métodos e recursos composicionais vêm tratando a questão da linguagem ao longo da história da música, no que diz respeito a semelhança, figuração e recursos harmônicos, como a progressão pela quinta que foi uma das principais aquisições do período barroco, no distante século XVII, ao cromatismo, que é a melhor conquista da obra composicional de Richard Wagner, já no século XIX. Esse processo de aproximação e distanciamento da linguagem acaba por orientar os compositores em dois sentidos diferentes, como já se pode imaginar, no sentido da semelhança com a linguagem e na direção oposta, ou como podemos dizer, afastando a música de qualquer correspondência significante e originando escolas composicionais como a música absoluta, representada por Krenek, por exemplo, assim como nosso principal objetivo e escola composicional mais próxima a Adorno, que é o dodecafonismo de Arnold Schonberg, e de maneira muita mais próxima, a transição mínima de Alban Berg, que é a técnica construtiva particular desse compositor, baseada em séries e fórmulas dodecafônicas aliadas ao tratamento retroativo dos elementos temáticos, conduzindo as melodias a uma articulação mínima, que por fim resultará, virtualmente, em uma única nota isolada. Embora não tenhamos o espaço necessário para um desenvolvimento que seja suficientemente amplo para considerar quatrocentos anos de música de concerto, nosso objetivo é traçar uma imagem de como a questão da linguagem se torna fundamental para a composição, e sobretudo como a alergia a essa semelhança se torna uma das principais características da nova música, essa que é produzida a partir do fim do século XIX e nas primeiras décadas do século XX. Para chegar a essa nova música de Schoenberg, Stravinsky, Berg, Webern e mesmo Hindemith, é necessário voltar os olhos para a antiga produção orquestral, muito embora nossa atenção a técnicas composicionais será concentrada no período pós Beethoven, em cuja obra podemos perceber 0 germe da expressão que construirá uma música menos formal, e por fim moderna. Nesse caminho dedicaremos alguma atenção a obras mais representativas de diversos períodos musicais, assim como da metafísica da música, ou para dizer mais claramente, das razões que sustentaram filosófica e esteticamente grandes composições. Palavras-chave: Música. Linguagem. Composição. Harmonia. Dodecafonismo.
\end{abstract}

Palavras-chave: Música. Linguagem. Composição. Harmonia. Dodecafonismo.

1 Mestre em Filosofia. E-mail: luizserranojґ@gmail.com. 
Dodecaphonism and musical language in Adorno:

\begin{abstract}
The resemblance between the abstract language of music and the conceptual signifying language of speech is one of the multiple aesthetic philosophical problems pointed by Adorno along his work, and will be the main object of this brief article, which intends to discuss some of Adorno's thoughts about music, in its intrinsic and almost indistinguishable relation with language. Part of the music history will be presented as introduction, as some musical examples. We will try to figure out how the compositional methods and resources have been treating the language question throughout the history of music, as it implies resemblance, figuration, and harmonic resources, as the fifth progression which was a main acquisition of the barroque period, at the distant 17th, to the chromatism which is the best achievement of the composition oeuvre by Richard Wagner, already at the 19th century. This process of approaching and taking distance from language ends up orientating compositors in two different directions, as one could imagine already, towards resemblance with language and on the opposite direction, as we could say, distancing music from any abstract signification and originating compositional schools as absolute music, represented by Krenek, for instance, and our main objective as Adorno's most close composition school, which is Arnold Schoenberg dodecaphonism and, in a much closer fashion, Alban Berg's minimal transition, which is Berg's particular constructive technique, based on series and dodecaphonical formulae, allied to his retroactive treating of the thematic elements, conducing the melodies to minimal articulation, ending up, virtually, on one isolated note. Although we will not have the needed space for a development which is enough wide to consider four hundred years of concert music, our objective is to trace a picture of how the language question becomes fundamental for the composition, and above that, how the allergy to that resemblance which is one of the main characteristics of the new music, which was the music produced since the end of the 19th and the first decades of the 20th century. To get to this new music of Schonberg, Stravinsky, Berg, Webern and even Hindemith, we must take a look back at the old production, although our attention to compositional techniques will be focused on the period post Beethoven, on whose work we can distinguish the very germen of the expression that will build a less formal and finally a modern music. In this path we must take some attention to very representative pieces of the various musical moments, as of the metaphysics of music, or, to speak more clearly, the reasons which led the great compositions to be made.
\end{abstract}

Keywords: Music. Language. Composition. Harmony. Dodecaphonism.

\title{
Blucher
}




\section{Panorama histórico}

0 objetivo desse breve artigo é discutir a relação entre música e linguagem, tanto em seu caráter imanente, ou seja, no que há de linguagem na música, quanto em seu aspecto formal, ou seja, no que diz respeito a aproximações e distanciamentos entre as linguagens musical e significante ao longo da história da composição. Faremos, portanto uma sucinta e necessária apresentação da questão da linguagem musical em algumas obras dos compositores mais importantes de seus períodos.

\section{Bach (1685 - 1750):}

É o pai da grande música de concerto. Foi também um homem de fé - compositor de música sacra nas mais diversas formas tais como missas, cantatas, réquiens - em uma época fortemente dominada pelo pensamento metafísico, que como não poderia deixar de ser, impregnava também a música enquanto forma de contato com o divino; uma função mística e de louvor era atribuída a esse tipo de música, e a composição parecia ser inspirada por forças divinas - é claro que à época também havia a música profana e a música popular, mas fogem de nosso campo de estudo. Afora essa motivação sobrenatural que envolvia a composição de Bach, estava uma evolução técnica que surgiria para modificar completamente a música que se fazia até o período: "só a introdução da tonalidade temperada, no século XVII, permitiu a modulação pela quinta, e, por conseguinte, Bach, que exprimiu o seu reconhecimento no título de sua grande obra para cravo." (ADORNO, 2002, 512) 
"O Cravo Bem Temperado" (1722) é uma conquista do sistema tonal. Partindo do ajuste dos intervalos físicos entre os sons e dividindo-os em doze intervalos iguais a escala musical foi uniformizada de forma que se obteve um sistema cíclico que permite que qualquer melodia seja transposta para qualquer tonalidade (por esse motivo 0 Cravo Bem Temperado contém estudos em todas as tonalidades); o passo seguinte é mais importante, pois de cada uma das notas, tomando como destino a quinta de sua escala, que por sua vez é um intervalo consonante e portanto soa natural, é possível fazer sucessivas modulações iguais e retornar ao tom original tendo passado por todos os doze tons.

Essa descoberta alimentou a pesquisa de outro compositor e estudioso da música da época; Jean Phillipe Rameau (1683-1764) estabelece em seu tratado de harmonia o papel de cada um dos graus da escala em relação à tônica. Parecia haver uma ordem entre os sons, e ela fora desvendada! A modulação pela quinta - e de forma geral o modelo musical tonal - permitiu que se estruturasse uma hierarquia entre as notas da escala dentro da tonalidade, assim como que se atribuísse uma função a cada grau. Que efeito deseja o compositor? Basta escolher o grau correto e assim se fará na música a suspensão, ou a tensão ou o relaxamento, ou a preparação, ou por fim a resolução, e isso se por mais uma modulação o compositor não quiser dar um novo rumo ao discurso musical, como veio a fazer abundantemente Richard Wagner. Claro que não se trata de dizer que a música barroca não tenha na expressão um de seus componentes, ou que não diga nada para além de sua aparência bem construída, o próprio filósofo faz essa ressalva: "Não há, consequentemente, praticamente nenhuma música que poderia ser chamada de sem expressão, e precisamente Bach, o objeto inatingível de toda a vontade objetiva no modernismo, mergulhou profundamente no reino da expressão" (ADORNO, 2002, 620)

\section{Blucher}


A forma construtiva, no entanto, tem muito mais força no processo de composição do que o conteúdo, de maneira que a música se constrói pelas regras de harmonia e então é preenchida melodicamente, como se percebe pela importância que Rameau atribuía à harmonia, relegando a melodia a um segundo plano, como se esta fosse consequência de uma construção harmônica correta.

0 período clássico, embora tenha seus grandes nomes, apresenta pouca variação em relação a essa maneira de compor, de forma que os métodos de que se utilizava Bach também estavam em Haydn (1732-1809) ou em Mozart (1756-1791), porém com uma variabilidade maior de motivos, de combinações harmônicas, e de maneira geral com uma intenção movida pela melodia, o que por um lado levava a música a uma beleza sem precedentes, mas por outro lado a esvaziava de conteúdo devido ao excessivo uso do adorno, do recurso estilístico, da orquestração brilhante, da repetição da frase bem construída e da variação sobre ela; ouvimos o Concerto para Clarinete K622 de Mozart e reconhecemos a frase melódica no Concerto para Piano K467, e assim em outras peças, bem como a já conhecida progressão pela quinta. A música de Mozart é comumente tratada como a mais bela que já se escreveu, e é bela de fato, mas ainda não é ela 0 objeto estético de que tratamos.

\section{Beethoven (1770-1827):}

É um momento de transformação importante na questão da linguagem musical, especialmente em sua obra de maturidade ; é importante colocar aqui com clareza o papel da expressividade que a música desse compositor incorporou e determinou não só como seu método composicional, mas 
como um estilo que influenciou muitos outros, o romantismo. Enquanto ainda o sistema tonal impera intocado em suas obras, sua forma de composição motívica supera a supremacia melódica do período clássico, atingindo uma dramaticidade que se tornou até confundível com a biografia do compositor, tido como introspectivo e infeliz. Não é sua felicidade que nos importa, e sim o uso que Beethoven também fez dos sistemas de progressões tonais, da harmonia funcional de Rameau e dos cânones formais de sua época, e quanto a isso sua música manteve as estruturas formais e construtivas comuns ao período; mas por ser dotada de um ímpeto ainda desconhecido a expressão adquiriu em sua obra um novo status, que pode se dizer que atribua preferência construtiva ao conteúdo musical, ou texto musical como se dirá a partir daí, o que por sua vez levou a harmonia a um novo patamar de desenvolvimento.

\section{Richard Wagner (1813-1883) e Richard Strauss (1864-1949):}

Não podem simplesmente ser colocados no mesmo balaio, mas muito do que um fez o outro replicou, a seu tempo, como uma continuação. A importância de Wagner é imensa, pois foi ele quem desenvolveu o sistema de modulação contínua, permitindo uma transição que levaria de qualquer a qualquer outra tonalidade, o que no limite criou o cromatismo que está em sua obra tardia. Também foi ele quem mais buscou uma aproximação entre música e linguagem significante, na tentativa da Gesamtkunstwerk, de forma que em sua obra operística existe uma submissão da música ao texto, que por Wagner era considerado de maior importância; essa submissão é uma das características da forma rapsódica da música, consolidada e amplamente produzida por Strauss na forma de poemas sinfônicos em uma interação cada vez maior com a literatura e a poesia. Muitos compositores viriam a adotá-la. 


\section{Arnold Schönberg:}

É o passo final dessa preparação. A técnica dodecafônica desenvolvida por ele consiste na utilização de todos os doze intervalos da escala musical, ao invés dos sete graus que caracterizam as escalas maior e menor, e de maneira geral a música tonal. Não é nosso objetivo esclarecer 0 funcionamento da técnica dodecafônica, o que tomaria um longo desenvolvimento, mas é possível apontar características que são intuitivamente compreensíveis ao leitor que não tenha formação musical, quais sejam, a recusa da forma de "melodia acompanhada", onde uma linha melódica discursa e os demais instrumentos a envolvem sonoramente (harmonicamente); a recusa da harmonia consonante, que consiste no uso dos acordes contidos no campo harmônico de cada tonalidade (além das dissonâncias geralmente utilizadas para preparação, suspensão etc.); a inclusão dos intervalos dissonantes na harmonia, aliás, a preferência por eles, assim como a construção harmônica baseada na série de doze tons; a rejeição da melodia acompanhada e eventualmente da escrita motívica, em favor da construção musical baseada em critérios diversificados, como as séries, que são sequências de notas organizadas segundo determinados critérios e a partir daí sofrem variações gerando o desenvolvimento do texto musical.

Temos um panorama histórico suficientemente traçado, o que nos permite fazer um estudo mais aprofundado a respeito da questão da semelhança entre música e linguagem, que, como veremos ao fim do trecho seguinte, foi o estopim das vertentes da música nova que tiveram lugar no fim do século XIX e início do século XX. 


\section{Linguagem musical}

A música sofre por sua similaridade com a linguagem e não pode escapar disto. Assim, ela não pode parar com a negação abstrata de sua similaridade com a linguagem. 0 fato de que a música, como linguagem, imita - de que na força de sua similaridade com a linguagem ela constantemente propõe uma sugestão, e ainda assim, como linguagem sem significação, nunca a responde - deve todavia, não nos desorientar a apagar esse elemento como mera ilusão. "Essa qualidade de ser uma sugestão, de dizer algo que o ouvinte entende e também não entende é algo que ela compartilha com toda a arte." (ADORNO, 2002, 122)

A similaridade da música com a linguagem é uma de suas características inegáveis e indissociáveis. Por determinista que pareça a frase anterior, é a essa conclusão que nos levará Adorno após um estudo sobre tal semelhança. Podemos ler assim o trecho em epígrafe, e teremos o problema da linguagem musical se apresentando. Vamos ver quais são seus aspectos principais e, sobretudo por que essa similaridade, segundo Adorno, constitui um problema, sobre o qual o dodecafonismo e seus compositores irão se debruçar em busca de emancipação da forma composicional.

Assim como a linguagem significante, a música consiste em um sistema organizado de sons que se desenrola ao longo do tempo, de maneira lógica, coerente e que, principalmente, diz algo, "geralmente algo humano" (ADORNO, 2002, 113). A semelhança não se esgota no que diz respeito à questão do desenvolvimento ao longo do tempo, como também envolve elementos que 
a linguagem musical toma de empréstimo da linguagem falada, como frases, perguntas, respostas etc.; o primeiro problema surge já nesse ponto: tendo sido consolidadas as funções harmônicas relativas aos tons da escala, conforme vimos em nossa introdução quando tratamos de Rameau e harmonia tradicional, surgiu daí uma invariância que não diz respeito somente à aplicação dos princípios de harmonia funcional como principalmente a sua significação abstrata, ou melhor dizendo, a linguagem musical que a princípio se distingue da linguagem significante por não poder ser traduzível em conceitos, passou a ter vocábulos constituídos pelos elementos formais da tonalidade que por sua vez passaram a apontar para conceitos musicais ; considerando que por não ser a música um sistema de signos que pretende compor um sentido textual a ser interpretado, retomamos o trecho em epígrafe e temos que sua natureza é dizer algo de forma oculta, ou apenas dar uma pista, uma sugestão, como aliás é o modo geral da obra de arte; essa associação direta e sempre constante, sempre utilizada com a mesma intenção, aponta justamente no sentido contrário, qual seja, aquele em que se direcionava a obra wagneriana, de associar os eventos musicais a um significado textual ou a um acontecimento operístico, por exemplo. A isso Adorno chama segunda natureza da música. 0 papel da tonalidade aqui não poderia ser mais desfavorável: tudo o que se construiu como recurso composicional desde o século XVII se tornou o significado implícito da música, ou do que é música, o que justifica a imensa resistência da "consciência em se separar da tonalidade"; existe ainda um aspecto sobre o qual vale lançar um pouco de luz, que é a intuitividade na percepção da música tonal que é decorrência direta de sua construção pelo uso dos intervalos consonantes, de forma que mesmo o leigo é capaz de sentir tal harmonia musical confortavelmente, ainda que sem conhecer música tecnicamente; as fórmulas de compasso definidas sempre em múltiplos de três ou quatro tempos são mais um dos elementos 
que foram naturalizados pelo uso metódico, e que quando começaram a ser utilizadas de maneiras diversificadas causaram um estranhamento semelhante ao que se sentiu diante das primeiras obras dodecafônicas em relação à dissonância; esse fundamento, aliás, se torna mais simples de ser contornado e passa a ser até exageradamente utilizado na música do século XX, pela combinação de compassos ímpares e pares, que resulta em compassos de sete ou onze tempos, por exemplo, e é muito utilizado por compositores que não romperam com a tonalidade mas inseriram em suas obras elementos vanguardistas, como Stravinsky, ou Hindemith, posteriormente, ou mesmo Shostakovich.

Retomemos nosso elo com Alban Berg e os demais compositores da Segunda Escola de Viena: a revolta desses compositores não é propriamente contra o aspecto linguístico da música, veremos que suas obras são permeadas por elementos de linguagem, assim como mantém 0 caráter narrativo que faz parte da tradição; a rejeição é em relação à versão reificada dessa linguagem, ou seja, o uso mecânico dos fundamentos composicionais como fórmula, a prevalência da forma, o esquematismo composicional tradicional - Alban Berg, por exemplo, logo no início na Suíte Lírica, implode a forma-sonata, para no desenvolvimento dar autonomia ao conteúdo musical. Existe ainda uma escola composicional que se apresentou como alternativa drástica ao caráter linguístico da música, qual seja, a linha da música construída a partir unicamente das relações entre as notas, que seria composta segundo princípios puramente musicais, ou seja, de combinação dos sons segundo leis de associação diversas, de forma a suprimir a semelhança com a linguagem. Há, porém uma característica fundamental da música que se perde nessa linha de composição, qual seja, a intenção. "Música sem qualquer significação, a mera coerência 
fenomenológica de tons, se assemelharia a um caleidoscópio acústico. Como significação absoluta, por sua vez, ela deixaria de ser música e passaria, falsamente, a linguagem. Intenções são essenciais a ela, mas aparecem apenas intermitentemente" (ADORN0, 2002, 114) .

A intenção surge na composição como um elemento que dá à obra musical sua alma, por assim dizer, e nos diz Adorno, atua na peça musical de forma dialética: sendo muito explícita a intenção, a música mais uma vez se torna linguagem e se perde nessa semelhança; onde, no entanto, não há intenção, a composição é desprovida de sentido e conteúdo musical. A intenção leva diretamente à questão da interpretação, pois diferentemente do que ocorre com a linguagem significante, interpretar a música não é compreendê-la e sim fazê-la. É uma linguagem, portanto, que não busca ser decodificada, porém mimetizada. A intenção é um elemento interno à obra musical, ela está orientando todo o processo composicional e sugerindo a todo momento significados abstratos; esses significados se realizam na interpretação; da mesma forma como não correspondem a objetos específicos e determinados, são também indeterminadamente interpretados, pois não constituem elemento de mediação, pois referem-se a si mesmos. A relação da linguagem musical com o absoluto é feita sem a mediação do conceito, que é a maneira da linguagem significante, então, enquanto essa busca 0 absoluto por sua mediação e nunca consegue atingi-lo, embora seja capaz de criar para esse ideias conceituais, a música toca diretamente 0 absoluto, porém não permite que essa experiência se consolide em conceitos. "A música alcança 0 absoluto imediatamente, mas no mesmo instante ele se ofusca, como quando uma luz forte cega os olhos, que não mais podem ver as coisas que são bem visíveis" (ADORNO, 2002, 116). 
Fizemos um caminho que nos trouxe do barroco até o século XX, e desse percurso extraímos duas formas composicionais predominantes que se instauraram como princípios estéticos musicais, quais sejam, a estética da forma e a estética da expressão, sobre as quais tratamos de maneira geral na introdução. Cada uma delas tem seu ponto fraco, por assim dizer; a primeira com sua tendência ao superficial devido ao exagero da preocupação formal e construtiva, a segunda correndo ao risco de perda da unidade devido ao desenvolvimento das partes particulares, como no caso de Wagner, por exemplo. Schönberg, no entanto, surge nesse horizonte com uma concepção que se oferece como alternativa para os modelos antigos, que não mais comportavam a música em sua complexidade técnica e construtiva, e em sua nova orientação que recusava o melodismo, por exemplo, além de outros elementos consolidados, a concepção de conteúdo musical.

Ao invés de partir de elementos como temas ou frases melódicas, acontece aqui um tipo de desenrolar autônomo do objeto composicional. A unidade que era encontrada anteriormente em um fundamento que orientava a obra, em suas diversas seções, agora está na maneira como cada momento musical irá conduzir ao seu próximo, e nessa relação contínua ir construindo a sintaxe da música. Como uma ideia abstrata, o conteúdo musical é aquilo que ocorre sob a estrutura da música, e que depende dela própria para se desenvolver, em uma relação dialética, 0 conteúdo dá a música que dá o conteúdo. Assim, temos, por exemplo o primeiro movimento do Quarteto de Cordas número 3, Opus 30 de Schönberg, que tem início com uma série relativamente simples de notas repetidas duas a duas pelo violino, esse elemento formativo vai sendo desenvolvido ao longo da peça, enquanto incorpora outros elementos, é modificado por eles, e continua seu desenvolvimento não mais vinculado a uma concepção de temas, mas baseado em

\section{Blucher}


si mesmo e no seu desenrolar. Berg utiliza-se de método semelhante, mas ao invés de incorporar novos elementos ao inicial, ele se orienta no sentido contrário, removendo os que lá estão em um processo retroativo e simplificante, por assim dizer, que tende à extinção dos temas. Sobre 0 conteúdo musical, leiamos mais um trecho:

Mas na verdade, o conteúdo musical é a riqueza de todas aquelas coisas ocultas sob a sintaxe e gramática musical. Cada fenômeno musical aponta além de si, com a força do que ele traz à memória, que é o que o distingue e o que nele causa expectativas. A essência dessa transcendência do elemento musical individual é o conteúdo: 0 que acontece na música (...) Pode se dizer que a música faz sentido quanto mais perfeitamente ela determina seu destino dessa forma, não somente quando seus elementos individuais expressam algo simbolicamente. Sua similaridade com a linguagem é completada à medida em que ela se distancia da linguagem. (ADORNO, 2002, 117).

É assim que se introduz no horizonte composicional a técnica dodecafônica de Schönberg e seus alunos, como uma "neve musical recém-caída na qual o sujeito ainda não deixou pegadas" (ADORN0, 2002, 119). Adorno usa essa figura para se referir aos acordes extraterritoriais utilizados por Schönberg na Noite Transfigurada, onde o desenvolvimento é muito mais cromático do que dodecafônico, mas esse uso inusitado de intervalos até então não previstos na harmonia tradicional (como 0 intervalo de quarta, no caso) foi o grande passo dessa escola, que rompendo com 0 tonalismo ampliou significativamente o espectro da linguagem musical, enquanto buscava se afastar dela. A subjetividade, tão demarcada no modo de compor do romantismo, dá lugar a uma objetividade que não é aquela arquitetônica como na forma composicional de Stravinsky, mas combina o método construtivo objetivo à intenção subjetiva do compositor, que atua no 
desenvolvimento do conteúdo musical em relação recíproca com o material musical, que agora adquire sua autonomia.

Temos então, para chegar de Bach a Berg, três importantíssimos pontos de ruptura na linguagem que podemos apontar sucintamente. Beethoven, no sentido da expressividade, tentando conciliar as intenções incontíveis com a forma tradicional e com os limitações do tonalismo, estética ainda imperante; Wagner, munido dessa expressividade e de um ferramental harmônico ainda não explorado baseado no cromatismo, levando a música a uma similaridade tão explícita quanto já foi possível com a linguagem significante, o que por sua vez gerou a alergia geral ao elemento linguístico na música e possibilitou o trabalho de Schönberg, que na rejeição da linguagem e na emancipação da dissonância permitiu a prevalência do objeto sobre o sujeito, ou a autonomia do conteúdo musical. Com essa linha sucessória chegamos ao ponto em que 0 desenvolvimento musical e sua relação com a linguagem são conciliados, segundo a visão de Adorno, na forma da obra de seu mestre:

Recordemos as óperas de Alban Berg. Nelas, lógica musical autônoma reina lado a lado com o elemento da linguagem musical wagneriana. Mais os dois princípios geram um ao outro em alternância. A pura articulação musical, a dialética, forma como-sonata pela qual Berg recupera esses próprios elementos - presentes no Classicismo Vienense e sacrificados por Wagner - tem sucesso precisamente na implacável força da imersão da música na linguagem, tanto literal quanto figurativamente (...) A música de Berg, tão distinta das tendências nivelantes que podem ser observadas nas mais diversas regiões da música nova, insistentemente manteve a variedade do conteúdo musical individual que oferece a essa unidade um resultado, e substancial, então a única razão é por que sua música obedece às intenções do texto em cada um de seus movimentos, de forma a tornar a música livre deles mais uma vez por meio da organização de sua coerência. Dessa forma, ela ganha um tipo de

\section{Blucher}


intervenção, algo como um processo envolvendo elementos concorrentes, e é isso que constitui sua seriedade. (ADORNO, 2002, 123 - 124)

Como havíamos antecipado, o esgotamento dos caracteres de linguagem na música ocasionou a chamada alergia dos compositores da nova música, mas para Adorno acontece na obra de Berg uma grande emancipação, que é o equilíbrio entre a autonomia musical, a semelhança com a linguagem e o rigor construtivo, o que propicia a obtenção de uma música sem concessões à aparência e ainda assim plena de expressividade. A música de Berg é o objeto da pesquisa da qual este trecho é introdução. 0 que se estudará a partira daqui serão seu métodos composicionais, sua Verbindlichkeit, e para dizer em uma palavra, o teor de verdade que norteia essas grandes obras da música nova, especialmente no trabalho operístico do compositor.

\section{Bibliografia:}

ADORNO, Theodor W. Berg: O mestre da transição mínima. São Paulo. Unesp. 2010 tradução Mario Videira.

. Music, Language and Composition in Essays on Music. Los Angeles. 2002.

. On The Problem of Musical Analysis in Essays on Music. Los Angeles. 2002.

. The Aging of the New Music in Essays on Music. Los Angeles. 2002.

. The Dialectical Composer in Essays on Music. Los Angeles. 2002. 
. On The Contemporary Relationship of Philosophy and Music in Essays on Music. Los Angeles. 2002.

. Wagner's Relevance for Today in Essays on Music. Los Angeles. 2002. . Late Style in Beethoven in Essays on Music. Los Angeles. 2002.

. The Opera Wozzeck in Essays on Music. Los Angeles. 2002. . Toward an Understanding of Schönberg in Essays on Music. Los Angeles. 2002. . On the fetish Character in Music and the Regression of Listening in Essays on Music. Los Angeles. 2002. 